\title{
UPAYA PENINGKATAN KESEHATAN USIA DIATAS 15 TAHUN DAN USIA LANJUT DI POSBINDU KELURAHAN KEMBANGAN SELATAN, JAKARTA BARAT (KEGIATAN LANJUTAN)
}

\author{
Ernawati $^{1}$, Rebekah Malik $^{2}$, dan Yoanita Widjaja ${ }^{3}$ \\ ${ }^{1}$ Bagian Ilmu Kesehatan Masyarakat, Fakultas Kedokteran, Universitas Tarumanagara Jakarta \\ Email: ernawati@fk.untar.ac.id \\ ${ }^{2}$ Bagian Patologi Klinik, Fakultas Kedokteran, Universitas Tarumanagara Jakarta \\ Email: rebekahm@fk.untar.ac.id \\ ${ }^{3}$ Bagian Patologi Klinik, Fakultas Kedokteran, Universitas Tarumanagara Jakarta \\ Email: yoanitaw@gmail.com
}

\begin{abstract}
Increased life expectancy is an advantage but at the same time becomes a condition that can be a source of problems in the health sector, especially non-communicable diseases. Currently non-communicable diseases that are often found are cardiovascular diseases such as high blood pressure, coronary heart disease, metabolic disorders such as diabetes, dyslipidemia, muscle and joint diseases such as arthritis, gout, osteoarthritis, nutritional disorders: obesity or malnutrition. The prevalence of various non-communicable diseases from 2013-2016 strokes increased from 7\% to $10.9 \%$; and chronic kidney disease rose from $2 \%$ to $3.8 \%$. Based on blood sugar tests, diabetes mellitus rose from $6.9 \%$ to $8.5 \%$; and blood pressure measurement results, hypertension rose from $25.8 \%$ to $34.1 \%$. The increase in the prevalence of non-communicable diseases is related to lifestyle, including smoking, consumption of alcoholic beverages, physical activity, and consumption offruits and vegetables. Problems require comprehensive handling and reach as broad as possible. One form of expansion of service coverage is posbindu. Posbindu in Kelurahan Kembangan Selatan is one of the posbindu that aims to provide comprehensive services to the age group > 15 years to make efforts to prevent non-communicable diseases and prevent complications for participants who have experienced interference so that no further complications occur. Activities are carried out routinely every month on Saturdays in the form of weighing, height, blood pressure, blood sugar levels, cholesterol and gout for every visitor of Posbindu. In addition to health checks, counseling activities are also carried out both individuals and groups and health consultations for visitors posbindu both experiencing health problems or not. This activity was carried out for 1 year from August 2018 to July 2019 (June Eid holidays) with the number of Posbindu visitors between 28-45 people with an average visitor 38. The average cases of high blood pressure were $33.45 \%$ (12), high cholesterol $27.24 \%$ (10), high blood sugar 24.74 (9), and high uric acid 19.87 (8). The results obtained for 1 year showed that the control of blood pressure, blood sugar, cholesterol and uric acid was still fluctuating even though counseling and consultation had been given based on the results of the examination. The conclusion from this activity shows that blood pressure, blood sugar, cholesterol and gout are not only influenced by regularity of control and knowledge but also diet, activity and environment. The advantage of this postbindu activity is that the health condition of visitors is monitored and health information can be conveyed on an ongoing basis. Suggestions for the future harmonious cooperation between health workers, patients and families / closest people of the patient must always be maintained through this posbindu activity.
\end{abstract}

Keywords: Posbindu; high blood pressure blood sugar; cholesterol; uric acid

\begin{abstract}
ABSTRAK
Peningkatan usia harapan hidup merupakan suatu keuntungan tetapi sekaligus menjadi suatu kondisi yang dapat menjadi sumber permasalahan di bidang kesehatan terutama penyakit tidak menular. Saat ini penyakit tidak menular yang banyak dijumpai adalah penyakit kardiovaskular seperti darah tinggi, jantung koroner, penyakit kelainan metabolik seperti kencing manis, dislipidemia, penyakit otot dan persendian seperti radang sendi, gout, osteoartritis, gangguan gizi: obesitas atau gizi kurang. Prevalensi berbagai penyakit tidak menular dari tahun 2013-2016 stroke naik dari 7\% menjadi 10,9\%; dan penyakit ginjal kronik naik dari 2\% menjadi 3,8\%. Berdasarkan pemeriksaan gula darah, diabetes melitus naik dari 6,9\% menjadi 8,5\%; dan hasil pengukuran tekanan darah, hipertensi naik dari 25,8\% menjadi 34,1\%. Kenaikan prevalensi penyakit tidak menular ini berhubungan dengan pola hidup, antara lain merokok, konsumsi minuman beralkohol, aktivitas fisik, serta konsumsi buah dan sayur. Permasalahan membutuhkan
\end{abstract}


penanganan yang bersifat menyeluruh dan menjangkau seluas mungkin. Salah satu bentuk perluasan jangkauan pelayanan adalah posbindu. Posbindu di Kelurahan Kembangan Selatan merupakan salah satu posbindu yang bertujuan memberikan pelayanan yang secara menyeluruh pada kelompok usia > 15 tahun untuk melakukan upaya pencegahan penyakit tidak menular dan mencegah komplikasi bagi peserta yang sudah mengalami gangguan agar tidak terjadi komplikasi lebih lanjut. Kegiatan dilakukan rutin setiap bulan pada hari Sabtu berupa penimbangan berat badan, tinggi badan, tekanan darah, kadar gula darah, kolesterol dan asam urat bagi setiap pengunjung posbindu. Selain pemeriksaan kesehatan, juga dilakukan kegiatan penyuluhan baik perorangan maupun kelompok dan konsultasi kesehatan bagi pengunjung posbindu baik yang mengalami gangguan kesehatan maupun tidak. Kegiatan ini dilakukan selama 1 tahun dari Agustus 2018 sampai Juli 2019 (Juni libur lebaran) dengan jumlah pengunjung posbindu antara $28-45$ orang dengan rata-rata pengunjung 38. Rata-rata kasus tekanan darah tinggi $33,45 \%$ (12), kolesterol tinggi 27.24\% (10), gula darah tinggi 24,74 (9), dan asam urat tinggi 19,87 (8). Hasil yang didapat selama 1 tahun ini menunjukkan bahwa pengendalian tekanan darah, gula darah, kolesterol dan asam urat masih naik turun walaupun sudah diberikan penyuluhan maupun konsultasi berdasarkan hasil pemeriksaan. Simpulan dari kegiatan ini menunjukkan bahwa tekanan darah, gula darah, kolesterol dan asam urat tidak hanya dipengaruhi oleh keteraturan kontrol dan pengetahuan tetapi juga pola makan, aktivitas dan lingkungan. Keuntungan dari kegiatan posbindu ini adalah termonitornya kondisi kesehatan pengunjung dan informasi kesehatan dapat tersampaikan secara berkelanjutan. Saran ke depannya kerjasama yang harmonis antara petugas kesehatan, pasien dan keluarga/orang terdekat pasien harus selalu dijaga lewat kegiatan posbindu ini.

Kata kunci: Posbindu, tekanan darah tinggi, gula darah, kolesterol, asam urat

\section{PENDAHULUAN}

Prevalensi berbagai penyakit tidak menular dari tahun 2013-2016 stroke naik dari 7\% menjadi 10,9\%; dan penyakit ginjal kronik naik dari $2 \%$ menjadi 3,8\%. Berdasarkan pemeriksaan gula darah, diabetes melitus naik dari 6,9\% menjadi 8,5\%; dan hasil pengukuran tekanan darah, hipertensi naik dari 25,8\% menjadi 34,1\%.(Kementerian Kesehatan, 2016)

Posbindu adalah pos pembinaan terpadu untuk masyarakat usia > 15 tahun dan usia lanjut di suatu wilayah tertentu yang sudah disepakati, yang digerakkan oleh masyarakat dan dibina oleh puskesmas atau institusi kesehatan untuk mendapatkan pelayanan kesehatan. Posbindu merupakan pengembangan dari kebijakan pemerintah melalui pelayanan kesehatan bagi usia $>15$ tahun dan lansia yang penyelenggaraannya melalui program Puskesmas dengan melibatkan peran serta para masyarakat usia >tahun, lansia, keluarga, tokoh masyarakat dan organisasi sosial dalam penyelenggaraannya. Posbindu merupakan wadah kegiatan berbasis masyarakat untuk bersamasama menghimpun seluruh kekuatan dan kemampuan masyarakat untuk melaksanakan, memberikan serta memperoleh informasi dan pelayanan sesuai kebutuhan dalam upaya peningkatan status gizi dan kesehatan masyarakat secara umum. (Kementerian Kesehatan, 2014, 2015, 2016)

Posbindu, saat ini telah menjadi salah satu strategi penting pemerintah (Kemenkes) untuk mengendalikan trend penyakit tidak menular yang semakin mengkawatirkan. Sebagaimana kita ketahui, berbagai data dan penelitian, menunjukkan bahwa trend tingkat kesakitan dan kematian penyakit tidak menular (hipertensi, diabetes, stroke, jantung, ginjal, dan lainnya), sudah melampaui tingkat morbiditas dan mortalitas penyakit menular. (Kementerian Kesehatan, 2014; 2015; 2016; Dinas Kesehatan DKI Jakarta, 2016; Notoatmodjo S, Krianto T, Hassan A, Mandy Z, 2013; Egger G, Spark R, Donovan R; Notoatmodjo, 2011)

Masalah kesehatan pada usia $>15$ tahun saat ini sudah berbeda, banyak penyakit metabolik yang terjadi akibat gaya hidup dan perilaku tidak sehat seperti pola makan, jenis makanan yang tidak seimbang serta aktifitas fisik yang kurang. Akibatnya kegemukan, kolesterol tinggi, kencing manis, darah tinggi dan ganguan metabolik lainnya bermunculan. (Kementerian Kesehatan, 2014; 2015; 2016; Dinas Kesehatan DKI Jakarta, 2016; Notoatmodjo S, Krianto T, Hassan A, Mandy Z, 2013; Egger G, Spark R, Donovan R; Notoatmodjo, 2011) 
Untuk lansia tentu saja berbeda dengan jenjang umur yang lain. Penyakit pada lansia merupakan gabungan dari kelainan-kelainan yang timbul akibat penyakit dan proses menua yaitu proses menghilangnya secara perlahan-lahan kemampuan jaringan untuk memperbaiki diri atau mengganti sel serta mempertahankan struktur dan fungsi normalnya, sehingga tidak dapat bertahan terhadap infeksi dan memperbaiki kerusakan yang diderita. Data penyakit lansia di Indonesia (umumnya pada lansia berusia lebih dari 55 tahun) adalah sebagai berikut: penyakit kardiovaskular seperti darah tinggi, jantung koroner, penyakit kelainan metabolik seperti kencing manis, dislipidemia, penyakit otot dan persendian seperti radang sendi, gout, osteoartritis, gangguan gizi: obesitas atau gizi kurang. Masalah kesehatan lansia di posbindu daerah Kelurahan Kembangan Selatan sama dengan data penyakit lansia di Indonesia. Oleh karena itu perlu upaya promotif dan preventif untuk mencegah sedini mungkin terjadinya penyakit dan komplikasi yang di akibatkan oleh proses degeneratif. (Kementerian Kesehatan, 2016; Dinas Kesehatan DKI Jakarta, 2016; Notoatmodjo S, Krianto T, Hassan A, Mandy Z, 2013; Egger G, Spark R, Donovan R; Notoatmodjo, 2011)

Ketua IKP SPS (Ikatan Keluarga Perumahan Serikat Penerbit Suratkabar) yang sudah bekerjasama dengan Fakultas Kedokteran Universitas Tarumanagara bermaksud tetap melanjutkan memberikan pelayanan kesehatan masyarakat di POSBINDU. Kegiatan pelayanan kesehatan di posbindu adalah upaya untuk meningkatkan wawasan dan kesadaran tentang kesehatan serta memantau kondisi kesehatan masyarakat yang aktif ke posbindu. Manfaat dari kegiatan Posbindu ini adalah meningkatkan pengetahuan tentang kesehatan sehingga mereka secara sadar mau melakukan upaya pencegahan lewat upaya perbaikan pola hidup dan kesadaran melakukan pemeriksaan kesehatan secara rutin/berkala ke posbindu. Sampai saat ini belum banyak anggota masyarakat yang rajin ke posbindu yang sudah merubah perilaku makan dan aktifitas fisik sesuai yang dianjurkan. Maka dibutuhkan kesinambungan kegiatan sampai sebagian besar masyarakatnya sadar. (Notoatmodjo, 2011, 2007; Supariasa IDN, 2002; Abdeyaz, 2013; Notoatmodjo, 2010)

\section{METODE PELAKSANAAN}

Kegiatan bakti kesehatan merupakan salah satu perwujudan Tridharma perguruan tinggi di bidang Pengabdian dan Pelayanan kepada Masyarakat (P2M) yang memerlukan peran serta dosen dan mahasiswa. Kegiatannya berupa pembinaan kegiatan posbindu, dimana bentuk pelayanan pada posbindu meliputi penyuluhan secara teratur dan berkesinambungan sesuai kebutuhan kesehatan usia > 15 tahun dan usia lanjut melalui berbagai media. Upaya ini dilakukan terhadap berbagai kelompok sasaran baik usia $>15$ tahun, usia lanjutnya sendiri, keluarga dan masyarakat sekitar. Melakukan penjaringan usia > 15 tahun dan usia lanjut risiko tinggi, pemeriksaan berkala seperti tekanan darah, berat badan, kadar gula darah, asam urat serta kolesterol, memberi petunjuk upaya pencegahan penyakit, gangguan psikososial dan bahaya kecelakaan yang dapat terjad pada kelompok usia lanjuti.

Penyuluhan ini merupakan salah satu cara untuk meningkatkan wawasan tentang kesehatan. Penyuluhan kesehatan merupakan bagian dari suatu pendidikan kesehatan kepada masyarakat dan kegiatan memberikan informasi secara jelas, mudah dimengerti serta dapat dilakukan berkelanjutan. Kegiatan bakti kesehatan akan diselenggarakan pada Agustus 2018 - Juli 2019 pukul 08.00 - 12.00 WIB di Posbindu Kembangan Selatan. Jl. Pemandangan D4/1, Komp SPS Puri Indah, Jakarta Barat. Luaran dari kegiatan ini berupa catatan kesehatan setiap pengunjung 
yang menjadi bahan Monitoring kader posbindu dan petugas kesehatan. Skema pelaksanaan bakti kesehatan dapat dilihat pada Gambar 1.

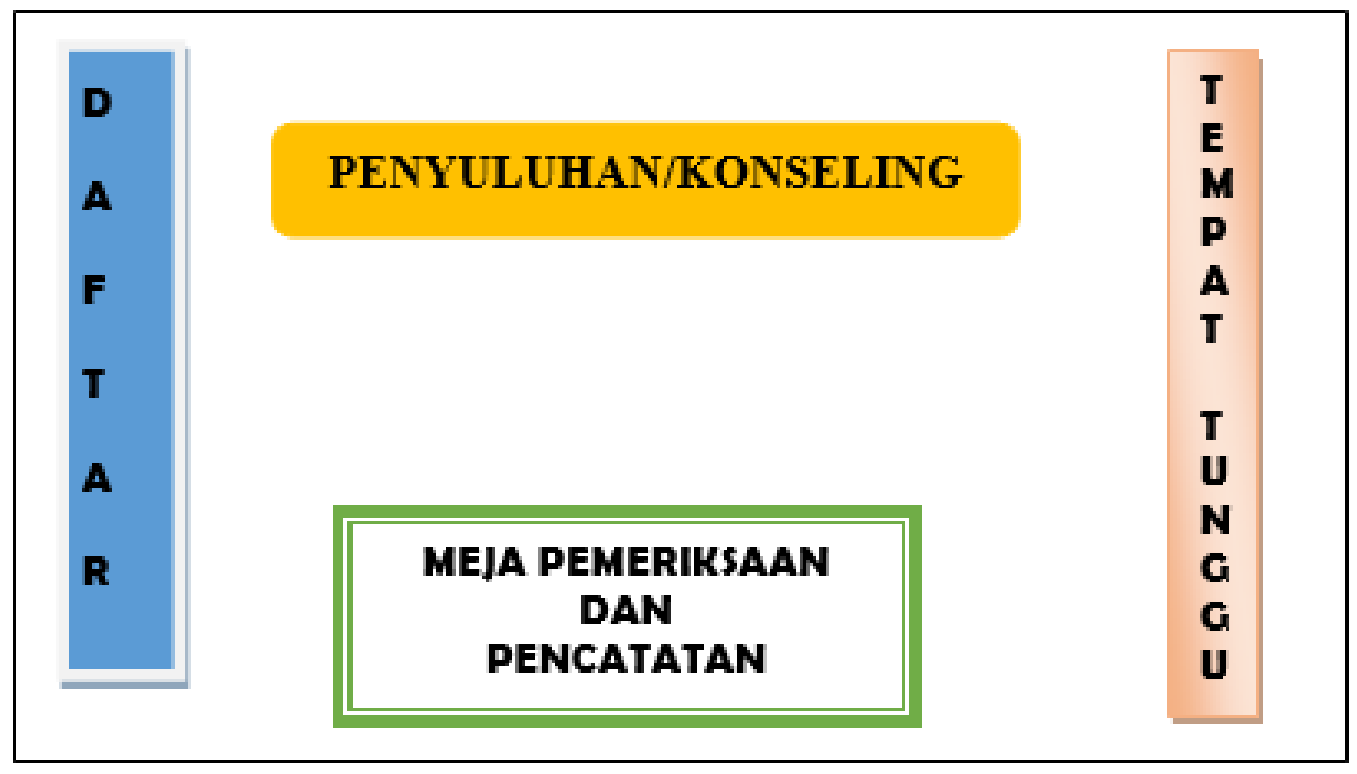

Gambar 1. Skema Pelaksanaan Bakti Kesehatan

\section{HASIL YANG DIDAPATKAN}

Kegiatan ini dilakukan oleh dosen, mahasiswa dari Fakultas Kedokteran Universitas Tarumanagara dan kader posbindu yang merupakan pengurus IKP SPS dan tokoh masyarakat di RW 04 Kelurahan Kembangan Selatan. Rata-rata kunjungan per bulan 38 dan rata-rata kasus tekanan darah tinggi 33,45\% (12), kolesterol tinggi 27.24\% (10), gula darah tinggi 24,74 (9), dan asam urat tinggi 19,87 (8). Pengunjung posbindu pada setiap bulannya lebih banyak pengunjung perempuan, rata-rata $>50 \%$. Hasil lengkap dapat dilihat pada tabel 1 di bawah ini.

Tabel 1. Hasil kegiatan selama 1 tahun

\begin{tabular}{llll}
\hline No & Waktu kegiatan & Jumlah pasien & Petugas \\
\hline 1 & 4 Agustus 2018 & 44 pasien $(28$ perempuan, 16 laki-laki) & Dokter \\
& & 17 tekanan darah tinggi $(38,64 \%)$ & Kader \\
& & 10 kolesterol tinggi $(22,73 \%)$ & Mahasiswa \\
& & 11 gula darah tinggi $(25 \%)$ & \\
& & 4 asam urat tinggi $(9,1 \%)$ & Dokter \\
2 & 1 September 2018 & 28 pasien $(20$ perempuan, 8 laki-laki) & Kader \\
& & 15 tekanan darah tinggi $(53,57 \%)$ & Mahasiswa \\
& & 4 kolesterol tinggi $(14,29 \%)$ & \\
& & 9 gula darah tinggi $(32,14 \%)$ & \\
3 & 5 Osam urat tinggi $(28,57 \%)$ & Dokter \\
& & 43 pasien $(29$ perempuan, 14 laki-laki) & Kader \\
& & 11 tekanan darah tinggi $(25,58 \%)$ & Mahasiswa \\
& & 4 kolesterol tinggi $(9,3 \%)$ & \\
4 & & 8 gula darah tinggi $(18,6 \%)$ & Dokter \\
& & 7 asam urat tinggi $(16,28 \%)$ & Kader \\
& & 34 pasien $(22$ perempuan, 12 laki-laki) & Mahasiswa \\
\hline
\end{tabular}


Usia Lanjut di Posbindu Kelurahan Kembangan Selatan, Jakarta Barat (Kegiatan Lanjutan)

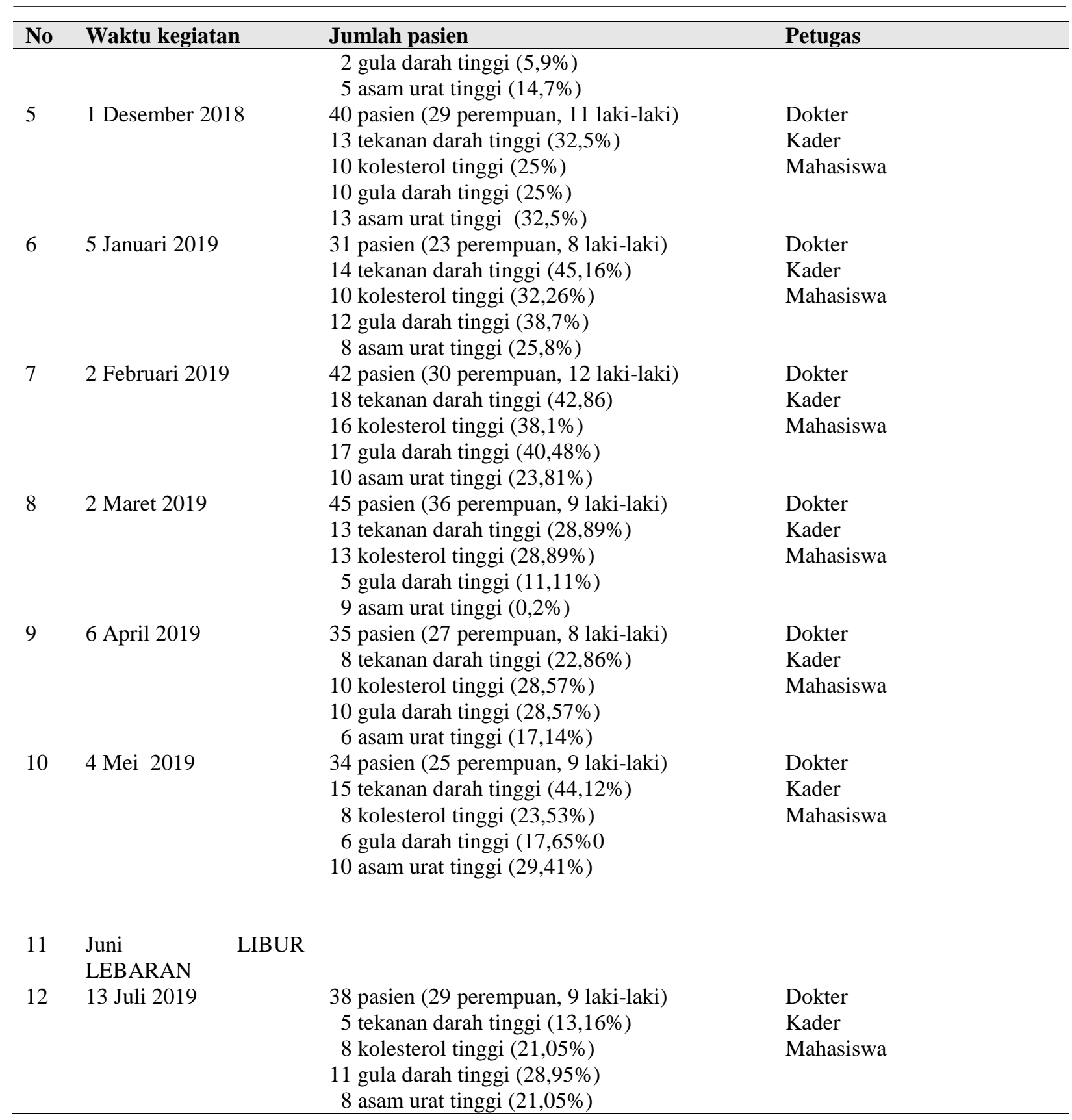

Jumlah kunjungan posbindu dapat dikatakan cukup stabil dan terlihat bahwa kesadaran warga akan pentingnya pemeriksaan berkala sudah cukup baik. Namun memang pengendalian terhadap tekanan darah, kolesterol, gula darah dan asam urat tidak dapat dilakukan dengan baik apabila tidak dilakukan secara menyeluruh mulai dari pola makan, pola aktivitas serta keteraturan berobat. Penyakit degeneratif dan metabolik memang hanya dapat dikendalikan tetapi tidak dapat disembuhkan serta membutuhkan kerjasama antara petugas kesehatan, kader, pasien dan keluarga/orang sekitar pasien.

\section{LUARAN YANG DICAPAI}

Pelaksanaan kegiatan berjalan sesuai perencanaan, lancar dan tertib. Target sesuai harapan untuk yang berusia > 15 tahun sampai usia lanjut dan tercatatnya data kesehatan terkait tekanan darah, gula darah, kolesterol dan asam urat pengunjung posbindu selama 1 tahun. 


\section{KESIMPULAN DAN SARAN}

Upaya untuk menjaga kondisi tekanan darah, kolesterol, gula darah dan asam urat memang membutuhkan upaya yang menyeluruh mulai dari menjaga pola makan, pola aktivitas, keteraturan kontrol dan minum obat. Keteraturan kontrol merupakan suatu upaya yang harus dilakukan secara rutin untuk memonitor kondisi kesehatan agar dapat segera dilakukan upaya antisipasi agar tidak terjadi komplikasi yang tidak diinginkan serta menjaga kualitas hidup pengunjung posbindu. Maka keberadaan dan peranan posbindu sangat besar, tidak hanya untuk memonitor kondisi kesehatan pengunjung tetapi juga merupakan salah satu wadah untuk silahturahmi dan sosialisasi bagi warga terutama yang lanjut usia. Menindak lanjuti hasil dari kegiatan ini, maka kegiatan PKM di posbindu harus dilakukan secara berkelanjutan dan kerjasama yang harmonis dengan semua pihak. Kegiatan PKM ini dapat juga melibatkan berbagai disiplin ilmu atau secara multidisplin melalui kerjasama fakultas lain serta tokoh masyarakat setempat untuk menyelesaikan permasalahan yang ada.

\section{Ucapan Terima Kasih (Acknowledgement)}

Penulis mengucapkan terima kasih kepada Direktorat Penelitian dan Pengabdian kepada Masyarakat (DPPM) sebagai sponsor dan Dekan Fakultas Kedokteran Universitas Tarumanagara (FK-UNTAR) yang mendukung penuh kegiatan penyuluhan ini. Tidak lupa penulis memberikan apresiasi kepada Ketua IKP-SPS dan ketua RW 04 Kelurahan Kembangan Selatan. Kader dan tokoh masyarakat dan Mahasiswa FK-UNTAR yang telah membantu sehingga kegiatan ini dapat berjalan dengan lancar selama 1 tahun ini.

\section{REFERENSI}

Abdeyaz. (2013). Promosi kesehatan teori dan aplikasi. Rineka cipta, Jakarta.

Badan Penelitian dan Pengembangan Kesehatan Kementerian Kesehatan Republik Indonesia. (2014). Riset Kesehatan Dasar tahun 2013. Jakarta: Kementerian Kesehatan Republik Indonesia.

Dinas Kesehatan DKI Jakarta. (2016). Profil Kesehatan Provinsi DKI Jakarta tahun 2015. Jakarta: Dinas Kesehatan DKI Jakarta.

Egger G., Spark R., Donovan R. (2013). Health promotion, strategies and methods. $3^{\text {rd }}$ edition. Australia: McGraw Hill.

Kementerian Kesehatan Republik Indonesia. (2015). Rencana Strategis Kesehatan 2015-2019. Jakarta: Kementerian Kesehatan

Kementerian Kesehatan Republik Indonesia. (2016). Profil Kesehatan Indonesia tahun 2016. Jakarta: Kementerian Kesehatan Republik Indonesia.

Notoatmodjo S. (2007). Promosi kesehatan. Ilmu dan perilaku. Jakarta: Rineka Cipta. .

Notoatmodjo, S. (2010). Pendidikan dan perilaku kesehatan. Rineka Cipta, Jakarta.

Notoatmodjo S. (2011). Kesehatan masyarakat ilmu dan seni. Edisi revisi. Jakarta: Rineka Cipta.

Notoatmodjo S., Krianto T., Hassan A., Mamdy Z. (2013). Promosi kesehatan global. Jakarta: Rineka Cipta.

Supariasa IDN. (2002). Pendidikan dan konsultasi gizi. W Dwi, editor. Jakarta: EGC. 